\title{
Modelling the multiscale behaviour of claystone: deformation, rupture, and hydro-mechanical phenomena around underground galleries
}

\author{
Benoît Pardoen ${ }^{1, *}$, Frédéric Collin ${ }^{2}$, Pierre Bésuelle ${ }^{3}$, Robert Charlier $^{2}$, Jean Talandier $^{4}$, Stefano Dal Pont ${ }^{3}$, Philippe \\ Cosenza $^{5}$, Abraham P. van den Eijnden ${ }^{6}$, Jacques Desrues ${ }^{3}$ \\ ${ }^{1}$ Univ. de Lyon, Tribology and Systems Dynamics Laboratory (LTDS, ENTPE), 69000 Lyon, France \\ ${ }^{2}$ Univ. de Liège, Urban and Environmental Engineering Department (UEE), 4000 Liège, Belgium \\ ${ }^{3}$ Univ. Grenoble Alpes, CNRS, Grenoble INP, 3SR, 38000 Grenoble, France \\ ${ }^{4}$ French national radioactive waste management agency (Andra), R\&D Division, 92298 Chatenay-Malabry, France \\ ${ }^{5}$ Univ. de Poitiers, Institut de Chimie des Milieux et Matériaux de Poitiers (IC2MP), 86000 Poitiers, France \\ ${ }^{6}$ Delft Univ. of Technology, Department of Geoscience and Engineering, 2600 Delft, Netherlands
}

\begin{abstract}
In the context of underground exploitation, the behaviour of rocks near galleries and tunnels conditions their stability. Underground drilling generates deformations, damage, fracturing, and significant modification of flow characteristics in the surrounding rock. However, the influence of small-scale characteristics and behaviour on the rock deformations and damage at engineering scale remains a complex issue. Consequently, the multiscale behaviour of a clay rock is modelled starting from the large scale of the excavation damaged zone around galleries and then enriching the approach by considering microstructural characteristics from the scale of mineral inclusions. Lastly, a double-scale numerical framework is considered. It allows to relate small- to large-scale rock behaviour in terms of deformations and material rupture. In fact, the development of damage and cracking at microscale allows to predict large-scale fracturing. The developed method focuses on a claystone in the particular context of long-term management of high-level nuclear wastes by deep geological repository. The results highlight the possibilities of double-scale computing in the prediction of the behaviour of underground engineering structures.
\end{abstract}

\section{Context}

The long-term management of high-level nuclear wastes is envisaged by deep geological repository. In this context, shales and clay rocks are considered as favourable host media. Due to the safety function of the host formation, the behaviour of the Excavation Damaged Zone (EDZ) that develops around underground galleries during their drilling is of paramount importance [1]. The EDZ is dominated by fracturing process which engenders irreversible modifications of the hydro-mechanical properties of the porous rock. In this zone, a significant hydraulic permeability increase of several orders of magnitude is observed [1,2]. It may alter the safety function of the host formation by creating preferential flow paths for the migration of radionuclides towards the biosphere. Therefore, the understanding and prediction of the EDZ hydro-mechanical behaviour are crucial issues for the long-term safe management of nuclear wastes.

Among the different low-permeability media that are envisaged for the deep repository, the Callovo-Oxfordian claystone (COx) is studied (Andra, France). It is an indurated fine-grained sedimentary rock with lowpermeability, cross-anisotropic structure, and quasihorizontal bedding planes. Claystones have a complex microstructure exhibiting multi-scale heterogeneities [3]. At meso-scale (i.e. the scale of mineral inclusions), the COx claystone is composed of several types of minerals with scattered mineralogical characteristics.

It is well known that large-scale phenomena (deformation, failure, hydro-mechanical coupling, etc.) take their origin from small scale processes, at grain and pore scale. Questions have risen on how microstructural characteristics of heterogeneous rocks can enrich the macroscale constitutive behaviour to predict deformation and failure processes. Consequently, the modelling of the hydro-mechanical behaviour of the clay rock is realised by considering its microstructural characteristics.

In the following, the behaviour of the COx claystone and its damage under mechanical solicitations are modelled at two scales. Following an engineering point of view, the macroscale behaviour of the EDZ is firstly studied with the development of shear fractures and permeability evolution [4-10]. Then, an insight of microdamage and micro-cracking is given by small-scale modelling [11-13]. This work is a synthesis of research results which highlights the possibilities of numerical prediction (deformation, rupture, and water flow) of EDZ in claystone, at small and large scales. Theoretical details are left aside but can be found in [4-15].

\footnotetext{
* Corresponding author: benoit.pardoen@entpe.fr
} 


\section{Macroscale}

A large-scale hydro-mechanical analysis of the EDZ is performed by reproducing numerically its behaviour (Lagamine FE code). Gallery excavations induce stress redistribution and fracturing in the surrounding rock. In the COx claystone, most of the observed fractures are in shear mode [1]. Thus, it is proposed to represent them in a continuous manner (by FEM) by strain localisation in shear bands [4-10]. Then, the development of fractures implies coupled processes and evolution of water transfers which are predicted around the underground excavation.

\subsection{Fracturing}

An appropriate model allowing to properly reproduce the strain localisation in geomaterials with finite element methods is used. It is an enhanced model for microstructure media called the coupled local second gradient model and which involves a regularisation method [16-17,8]. It allows considering unsaturated anisotropic rocks with compressible solid grains and permeability evolution [6-8].

The used mechanical constitutive model is an anisotropic elasto-plastic internal friction model (Van Eeckelen yield surface) with non-associated plastic flow. It allows hardening and softening of friction angle and cohesion, calibrated on experimental data. A second gradient mechanical law is also defined. It is an isotropic linear elastic law function of the (micro) second gradient of the displacement field. It introduces an internal length scale to which the shear band thickness is related. Furthermore, the hydraulic flow is governed by advection (Darcy law), water retention and permeability curves (Mualem - Van Genuchten's model). The effective stresses under unsaturated conditions are defined by Biot's definition [8]. It includes the compressibility of the solid grains relative to the skeleton compressibility.

The gallery excavation modelling is performed by reducing the pressure at gallery wall following a deconfinement rate related to the drilling speed. Firstly, a modelling in 2D plane-strain state is performed considering both structural and stress state anisotropies $\left(\sigma_{\text {hor }}=\sigma_{\text {vert }}=12 \mathrm{MPa}, \sigma_{\text {Hor }}=15.6 \mathrm{MPa}\right)$. The results of the EDZ development (shear bands) at the end of excavation are detailed in Fig. 1 for two gallery orientations (in terms of total deviatoric strain $\hat{\varepsilon}_{e q}=\sqrt{\frac{2}{3} \hat{\varepsilon}_{i j} \hat{\varepsilon}_{i j}}$. Fig. 1a concerns a gallery parallel to the minor principal horizontal stress $\left(\sigma_{\text {hor }}\right)$ with an anisotropic initial stress state in the gallery section $\left(\sigma_{\text {Hor }}>\sigma_{\text {vert }}\right)$. The chevron shear fractures appear during the excavation and develop preferentially above the gallery, in the direction of the minor principal stress [8]. Fig. 1b concerns a gallery parallel to the major principal horizontal stress $\left(\sigma_{\mathrm{Hor}}\right)$ with an isotropic initial stress state in the gallery section $\left(\sigma_{\text {hor }}=\sigma_{\text {vert }}\right)$. In this case, the shear bands develop preferentially in the horizontal direction, the direction of material weakness [7].

This is related to the anisotropic evolution of material cohesion (plastic anisotropy) during material unloading.
It means that the development and shape of the EDZ are mainly dictated by the anisotropy of both in situ stress state and material resistance.

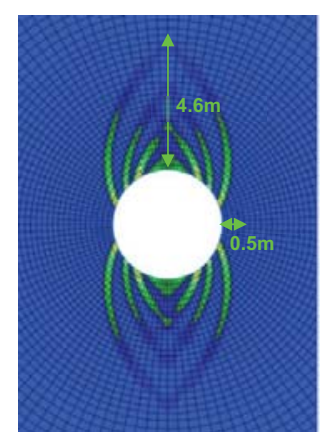

(a)

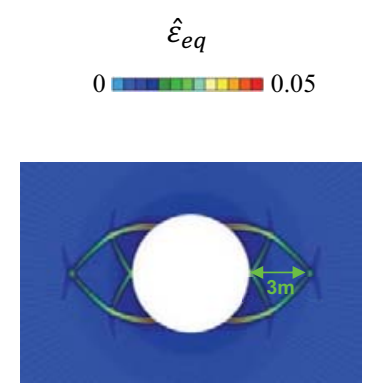

(b)
Fig. 1. EDZ in claystone by shear band representation for galleries parallel to the (a) minor $\sigma_{\mathrm{h}}$ and (b) major $\sigma_{\mathrm{H}}$ principal horizontal stresses [5-8].

The gallery convergences are also detailed in Fig. 2 for the gallery oriented parallel $\sigma_{H o r}$ (Fig. 1b). Both horizontal and vertical convergences (variations of gallery diameter) are depicted and compared to experimental data [18]. The latter are in situ measurements performed by the Andra in their Underground Research Laboratory (GCS gallery). The numerical results indicate that the anisotropy of the gallery convergence is well captured with a larger convergence in the direction of the fractures appearance [5-8]. This cannot be reproduced without the development of shear bands. Moreover, creep deformations have been introduced with a viscoplastic mechanism (i.e. delayed viscoplastic strain) to reproduce the increase of convergence in the long term [5].

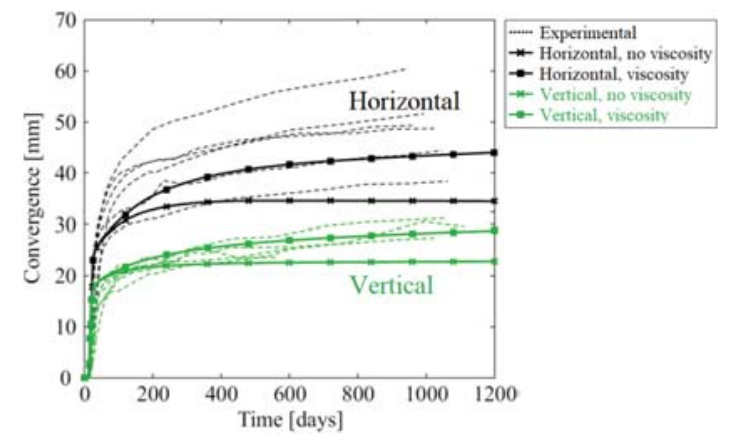

Fig. 2. Long-term evolution of horizontal and vertical convergences of a gallery parallel to the major horizontal principal stress $\sigma_{\mathrm{H}}[5]$.

Furthermore, fracturing around galleries develops in all directions, not only around them but also in front of the excavation front [1]. A 3D modelling of gallery excavation is thus also performed. The geometry of a quarter of a gallery parallel to $\sigma_{\text {hor }}$ is fixed $\left(\sigma_{x}>\sigma_{y}\right.$ in the gallery section) and the pressure at gallery wall is progressively reduced as previously. Fig. 3 highlights the development of shear bands around a gallery at successive stage of the excavation: (a) $70 \%$, (b) $75 \%$, (c) $80 \%$, and (d) $85 \%$ of deconfinement. On this figure, the view point is located at the gallery axis and looks over the curved gallery wall and the flat gallery front (see the black lines). One can observe the development of shear bands in the 
rock parallel to the gallery wall and ahead of the excavation front.

The results indicate that the numerical modelling of the fractured zone with shear banding provides information about its shape, extent, fracturing structure, and behaviour that are in good agreement with in situ measurements (Fig. 1, Fig. 2, Fig. 3). In particular, the shape of the EDZ in the claystone is governed by its anisotropy and the gallery convergence strongly depends on the appearance of the shear bands.

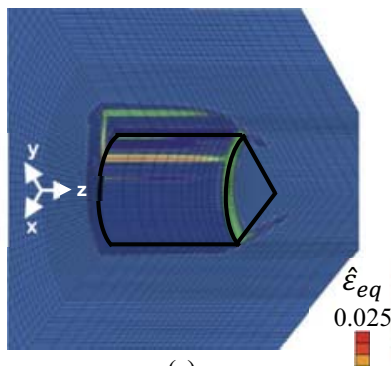

(a)

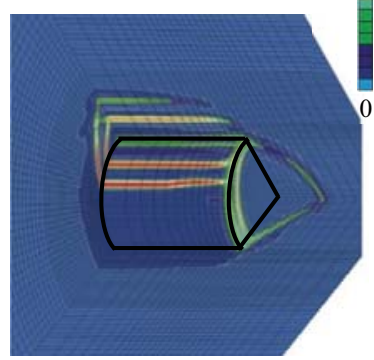

(c)

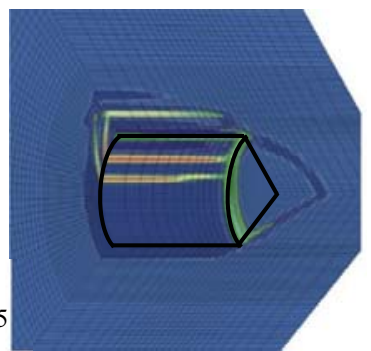

(b)

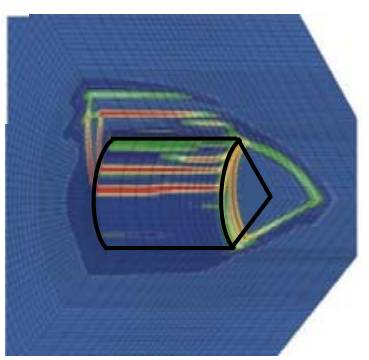

(d)
Fig. 3. 3D modelling of the development of the EDZ by shear banding around a gallery at successive stages of excavation: (a) $70 \%$, (b) $75 \%$, (c) $80 \%$, and (d) $85 \%$ of deconfinement.

\subsection{Fluid transfers}

The fluid transfers and the coupled hydro-mechanical processes are investigated in the EDZ. The impact of the rock fracturing on its hydraulic properties is addressed by taking into account strain localisation effects at macroscale. The evolution of the intrinsic water permeability is expressed by a strain-dependent relation which engenders a more pronounced increase of the permeability inside the shear bands [6]. Fig. 4 details the evolution of intrinsic water permeability in the rock, in terms of orders of magnitude. The later is represented by the ratio of the intrinsic (saturated) water permeability tensor $\mathrm{k}_{\mathrm{ij}}$ by its initial value $\mathrm{k}_{\mathrm{ij}, 0}$. Results are shown at $66 \%$ and at the end of excavation. The numerical results concern the vertical direction of a gallery parallel to the minor horizontal principal stress $\sigma_{\mathrm{h}}$. They are compared to experimental data from the Andra [1,6] measured along vertical boreholes drilled around the GED experimental drift [6]. In agreement with these experimental measurements, an important increase is reproduced in the excavation damaged zone (Fig. 4), especially in the shear bands (near field). The increase amplitude is representative of the fracture permeability. Moreover, the continuous rock matrix permeability of damaged (mid field) and undamaged rock (far field) are also well captured.

After gallery excavation, the hydraulic transfers in the rock surrounding the galleries are investigated by considering the interaction between the rock and the gallery air. These transfers are studied at large scale during the reproduction of gallery air ventilation. The Andra performed a large-scale ventilation experiment called Saturation Damaged Zone experiment (SDZ) in an experimental gallery (GED) [6,9] to investigate the unsaturated behaviour of COx claystone. Depending on the air hygrometry, the gallery air ventilation implies drainage and desaturation of the surrounding rock.

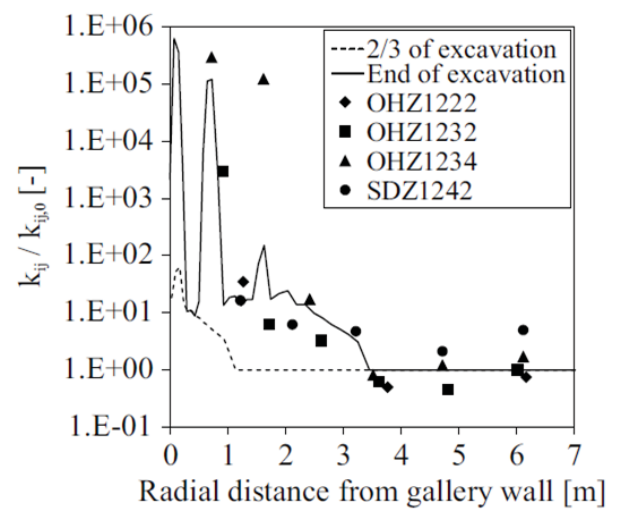

Fig. 4. EDZ in claystone by reproduction of the water intrinsic permeability evolution in the vertical direction around a gallery parallel to $\sigma_{\mathrm{h}}[6]$.

The hydraulic transfers in the rock which depend on the water exchanges at gallery wall are also studied. The air-rock water transfers are considered through a nonclassical mixed hydraulic boundary condition $[6,9,19]$. This condition implies that two modes of exchange can occur at the gallery wall of ventilated cavities: liquid water and water vapour exchanges. The latter consist of progressive hydraulic transfer kinetics for which, in the long term, a thermodynamic equilibrium is reached between the gallery wall rock and the gallery air. In the modelling, the evolution of gallery air hygrometry (i.e. relative air humidity) during time is applied through this condition.

The water drainage (i.e. pore water pressure $p_{w}$ reduction) in the rock caused by the gallery air ventilation is reproduced in Fig. 5. The numerical results are compared to experimental measurements performed in a horizontal borehole drilled from the SDZ experimental zone. Several sensors were placed at increasing distances in the rock ( 3 to $20 \mathrm{~m}$ depth). They allow to evaluate the influence depth of the ventilation and the desaturation of the EDZ [6]. In fact, one can observe suction $\left(\mathrm{p}_{\mathrm{w}} \leq 0\right)$ deeper than $3 \mathrm{~m}$ after 1500 days of ventilation. This rock desaturation is due to the increase of permeability in the EDZ and to the water drainage [6].

These results prove the ability of the model to predict coupled processes and fluid transfers in the EDZ and deeper in the surrounding rock [6]. 


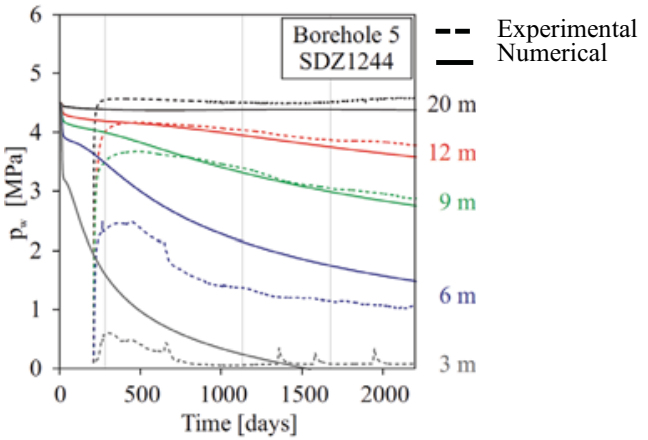

Fig. 5. Water drainage in claystone compared to experimental measurements in a horizontal borehole and at different distances from the gallery wall [6].

\section{Microscale}

Clayey rocks have a heterogeneous structure at various scales. When considering the scale of mineral inclusions in COx, which are embedded in a clay matrix, deformations often engenders microdamage and microcracking, responsible of permeability change. Modelling these processes requires considering microscale properties and their effect on the micromechanical response [11-15]. The main objectives are to consider realistic heterogeneous microstructures allowing the prediction of deformation and damage mechanisms from the microscale.

\subsection{Representative microstructure}

Heterogeneous numerical microstructures are generated with a distribution of grain morphological properties satisfying experimental characterisations of the material [11-13,20,21]. These microstructures are considered as 2D microscale Elementary Areas (EA) which are defined in order to be both a realistic and simple representation of the clay rock's microstructure. An example of realistic microstructure of COx claystone with a characteristic size of $100 \times 100 \mu \mathrm{m}$ is visible in Fig. 6a.

(a)
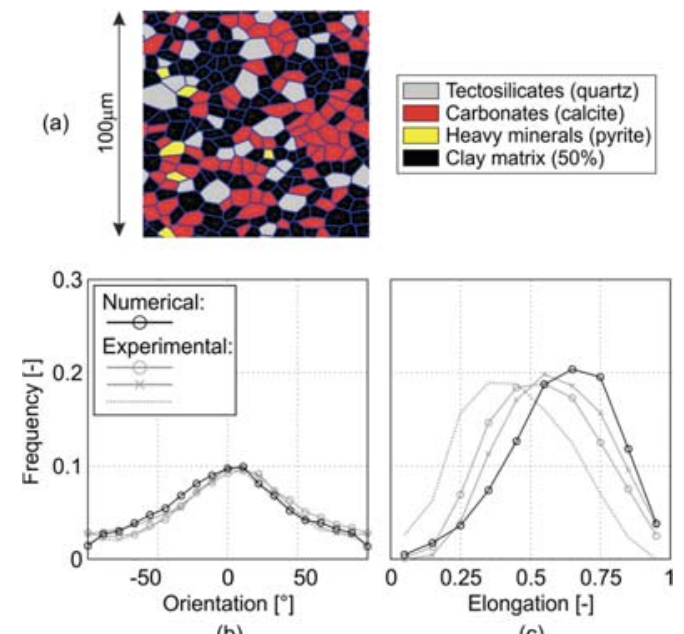

(b)

Fig. 6. Microstructure representativeness: (a) example of numerical elementary area and $(b, c)$ comparison of experimental and numerical morphological characteristics of calcite [11].
The EAs are developed to represent the grains and the failure modes at meso-scale [14,15]. The EAs contain solid grains defined by cells, each cell representing a mineral inclusion or a clay grain (Fig. 6a). The solid grains are elastic deformable solids separated by damageable cohesive interfaces. Cohesive forces are described by a damage law, allowing softening of the material due to deformation. Boundary conditions are periodic. Large deformations may develop at microscale and are mainly concentrated at grain contacts. Thus, potential cracks are considered at grain interfaces which allows two failure types as observed in the clay rock [22]: decohesion around inclusions and intergranular microcracking within the clay matrix. A variability of the mineralogical characteristics is also considered to reproduce the inclusion morphology (orientation, elongation) and the spatial distribution of clay and minerals (Fig. 6b-c, [11]).

Additionally, the grain interfaces form a porous network allowing fluid transport prescribed by the variation of interface opening which leads to a variation of the material permeability. In fact, the hydraulic permeability of the material (homogenised over the EA) is the direct result of the water flow within the microstructure through the interfaces [14]. With fluid pressure acting on the solid parts, this gives a coupled hydro-mechanical system at the micro level $[14,15]$.

\subsection{Response and damage}

The clay rock micromechanical behaviour is analysed through the responses of EAs under solicitation. The overall stress-strain response is obtained by numerical homogenisation with microscale finite element computation [14,15]. A 2D plane-strain biaxial compression is modelled with a confining phase of $\sigma_{3}=12$ MPa followed by a vertical compression. The variability of material response and deformation under deviatoric solicitation are analysed regarding small-scale characteristics [11].

For calibrated micromechanical parameters (of mineral constituents and their contacts) [11], stress-strain deviatoric response curves are detailed in Fig. 7. They present the evolution of the global deviatoric stress $\mathrm{q}=\sigma_{1_{1}}$ $\sigma_{3}$ with the homogenised vertical $\varepsilon_{1}$ and lateral $\varepsilon_{3}$ strains of the EAs. Numerical results in Fig. 7a indicate that, for a constant EA size of $100 \times 100 \mu \mathrm{m}$, the microscale overall response shows some dispersion due to the variability of the microstructures (variable inclusion positions, mineral contents, and grain morphology). In particular, the clay content varies from $40 \%$ to $60 \%$ [20]. Since mineral inclusions are stiffer than the clay matrix, a lower clay content leads to a stiffer response of the EAs [11]. This scattering suggests that the chosen EA size, based on grain morphology, may not be sufficient regarding the mechanical response.

In fact, the representativeness of the microstructure in the elementary area and of its mechanical response depends on its size. The effect of microstructure size is then analysed in Fig. 7b for 50x50, 70x70, and 100x100 $\mu \mathrm{m}$ with a fixed $50 \%$ of clay content. For each case, the 
range of response curves is illustrated. They correspond to the most and least resistant responses of sets of 10 tested EAs for each microstructure size. The variability of the overall response reduces with increasing size which mitigates the partial lack of EA representativeness.

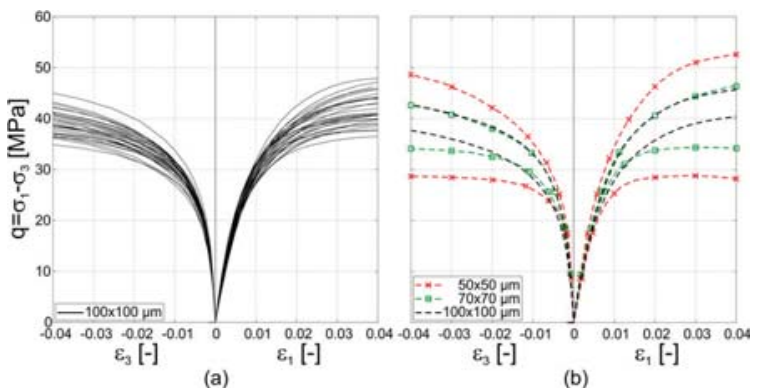

Fig. 7. Microscale response variability: to (a) randomness of EA generation and mineral contents and (b) microstructure size [11].

Then, small-scale material deformation and failure within the microstructure are analysed. One microstructure with $60 \%$ of clay content is studied to enlighten grain movements and micro-damage of grain contacts. The response curve and the small-scale deformation are detailed in Fig. 8. A peak deviatoric stress followed by strain softening occurs (Fig. 8a), with the amplitude of material softening depending on the grain interface properties. Furthermore, microscale deformations are detailed at several stages of the vertical loading (Fig. 8b), before $\left(\varepsilon_{1}=0.01\right)$ and after peak stress $\left(\varepsilon_{1}=0.05,0.1\right)$. Cohesion softening and complete decohesion at grain contacts (i.e. partially and fully damaged contacts) are indicated by graphical symbols in Fig. 8b. Before peak stress, the microstructure deformation remains limited. Then, damage increases, coalesces, and forms a microcrack propagating through the entire EA. This induces important grain displacements (mainly sliding, Fig. 8b) and a global softening behaviour of the micro-structure (Fig. 8a). A dominant shear deformation and damage mode is observed between grains. However, microscopic deformations are localised in the EA with only a small proportion of interfaces reaching complete decohesion (Fig. 8b).

A deeper analysis of the influence of microscale characteristics on the homogenised material response and microcracking pattern is investigated in [11].

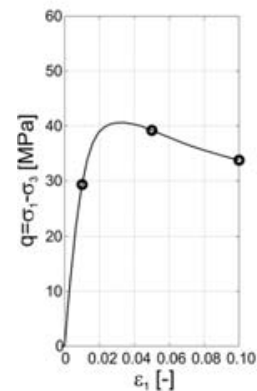

(a)

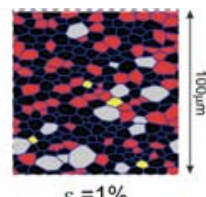

$\varepsilon_{1}=1 \%$

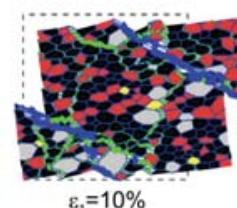

(b)
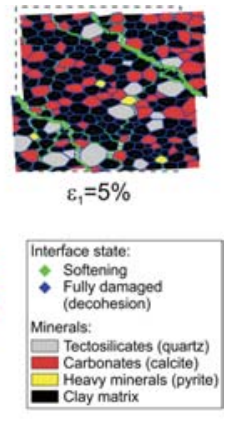

Fig. 8. Microscale behaviour: (a) material response and (b) development of micro-damage and micro-cracking [11].

\section{Double scale}

The overall response of the microstructure can be used in a double-scale approach to predict the material behaviour at larger scale. This is embedded in a double-scale finite element ( $\mathrm{FE}^{2}$, Lagamine code) approach by computational homogenisation $[14,15,23,24]$. The overall response of the microscale EA serves as a homogenised numerical constitutive law for the macroscale. However, the chosen EA size has to remain limited due to numerical constrains for double-scale approach. At macroscale, a poromechanical continuum is defined with fully coupled hydro-mechanical behaviour and a regularisation method (second gradient model [16-17,8]). The proposed numerical approach allows to take into account the smallscale heterogeneity and spatial variability with its effects from small to large scale ([11-13]).

A double-scale computation of a biaxial compression (confining pressure of $\sigma_{3}=12 \mathrm{MPa}$ ) on a larger laboratory specimen (centimetric scale) is considered in a $2 \mathrm{D}$ planestrain state. The clay rock specimen is initially saturated (nil initial pore water pressure) and is globally drained on its bottom and top surfaces (lateral surfaces are impervious). The results in Fig. 9 highlight the claystone response curve at micro and macro scales [12]. The macroscale global response of the specimen (double-scale approach) is compared to the numerical microscale EA response and to experimental data of compression tests [25]. The experimental results are satisfactorily reproduced by the modelling. The difference between the macro and micro scales response curves is due to strain localisation at macroscale (Fig. 10), with the post-peak behaviour related to the macro shear banding process.

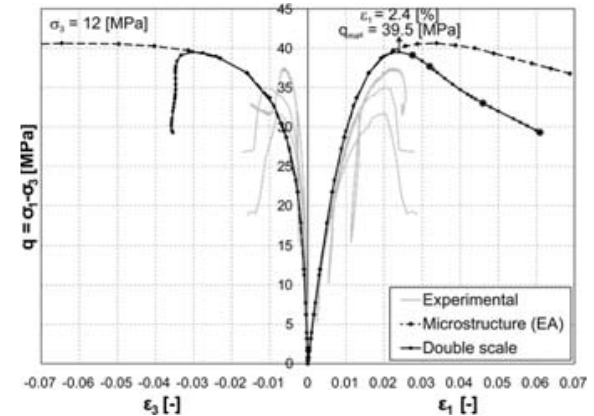

Fig. 9. Double-scale response: influence of macroscale shear banding with comparison to microscale response and experimental data [12].

Fig. 10 highlights material deformation and failure with a focus on the relation between the microscopic and macroscopic scale processes. At macroscale, the shear deformations $\hat{\varepsilon}_{e q}$ are detailed (Fig. 10a) during the compression test (increasing values of specimen's vertical deformation $\varepsilon_{1}$ ) and indicate the formation of a shear band throughout the specimen, after peak stress. At microscale (i.e. EA scale), the behaviour is detailed with the microstructure evolution within the shear band (Fig. 10b). Microscale deformations are considerable in macroscopic finite elements inside the shear band. However, the microstructure remains almost undeformed far from the shear band, where macroscopic deformation is low. 


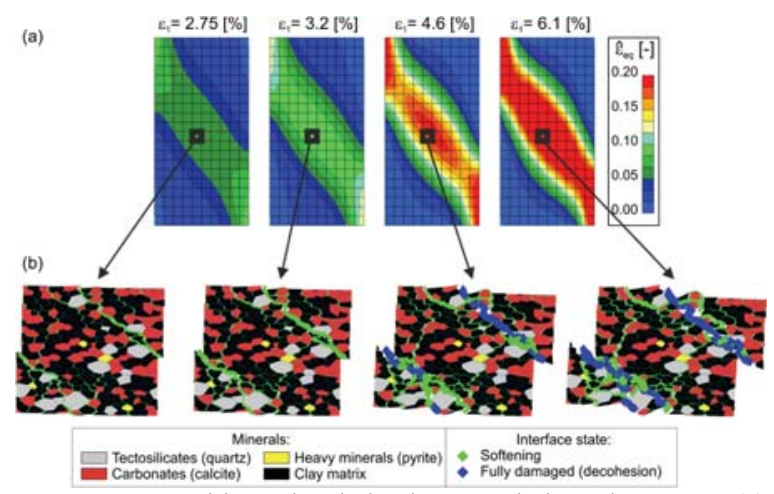

Fig. 10. Double-scale behaviour: relation between (a) macroscopic shear banding and (b) microcracking in post-peak regime [12].

After reproducing the clay rock behaviour at mesoscale and at laboratory scale, such double-scale method can also be used to predict the damage and fracturing at the engineering scale. Preliminary computations of gallery excavations with relatively simple microstructures of COx claystone have been realised in [15]. They highlight the micro-macro damage relation and the possible reproduction of the shear fractures around underground structures as depicted in Fig. 11.

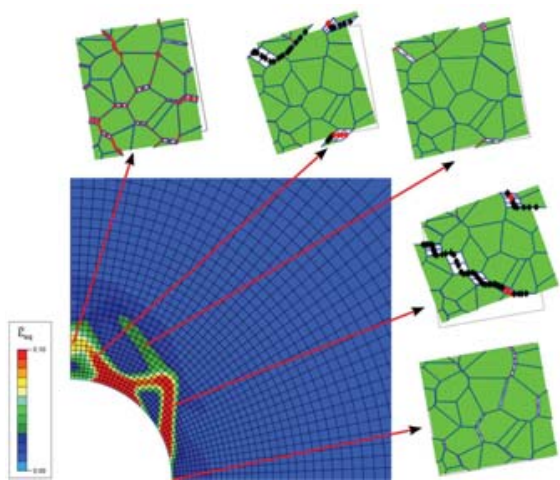

Fig. 11. Fractured zone around underground (quarter) gallery with microstructural effects in the scope of a double-scale $\mathrm{FE}^{2}$ modelling [15].

\section{Conclusion and perspectives}

The proposed approach aims to highlight the important multi-scale aspects to consider for the reproduction of the EDZ behaviour in clay rock. The focus is placed on the numerical modelling of both microscopic and macroscopic behaviours of damaged rock, based on experimental measurements. At the scale of underground structures, the macroscale model allows to reproduce the shape of the shear fracture zone, its size, its hydraulic permeability increase, as well as the drainage of the surrounding rock. At the scale of mineral inclusions, the microscale model allows to reproduce the micro-damage and micro-cracking while considering the morphology and heterogeneity of mineral inclusions. Furthermore, the double-scale modelling shows the relation between smalland large-scale behaviours in terms of deformations and material response. The results highlight the possibilities to consider microstructural characteristics in the modelling of rock damaged zone related to engineering applications.
To go further, various perspectives are envisaged: - Large-scale drilling modelling can now be performed with the developed more realistic microstructures.

- On large or intermediate scales, the natural heterogeneity of clay rocks can be improved by a spatial variability of the EAs (at the Gauss points of the macroFE-model). This can partially solve the lack of EA representativeness related to its restricted size for doublescale computing.

- Small-scale characteristics of grain morphology (e.g. elongation, orientation) should be studied to explain the macroscale anisotropic response of sedimentary rock.

- The properties of mineral contacts condition the overall microscale deformations and response. They should be deeper analysed based on experimental evidences and related to the mechanical energy dissipation phenomena during crack opening.

- Hydraulic permeability of rock masses increases with the degree of fracturing. Efforts should be done to relate microcracking and macroscale permeability evolution [14]. Microcracks can lead to grain contact apertures in the EA. The latter engender an increase of the overall hydraulic conductivity and water flow through the microstructure. However, the fracture water permeability of COx claystone decreases with material swelling and self-sealing of cracks during resaturation [26]. This reduction is firstly induced by the swelling of certain clay minerals present in the argillite (due to clay-water interactions). One of the major current issues for Andra is to take into account this recovery of fracture water permeability (i.e. self-healing) in constitutive models. The micro-macro approaches and the consideration of mineralogical distribution are certainly interesting pathways to represent these important processes for the evaluation of transfers in the repository.

\section{References}

1. G. Armand, F. Leveau, C. Nussbaum, R. de La Vaissiere, A. Noiret, D. Jaeggi, P. Landrein, C. Righini. Geometry and properties of the excavation-induced fractures at the Meuse/Haute-Marne URL drifts. Rock Mech. Rock Eng. 47:21-41 (2014)

2. C.F. Tsang, F. Bernier, F., C. Davies. Geohydromechanical processes in the Excavation Damaged Zone in crystalline rock, rock salt, and indurated and plastic clays - in the context of radioactive waste disposal. Int. J. Rock Mech. Min. Sci. 42:109-125 (2005)

3. B. Yven, S. Sammartino, Y. Geraud, F. Homand, F. Villieras. Mineralogy, texture and porosity of CallovoOxfordian argillites of the Meuse/Haute-Marne region (eastern Paris Basin). Mém. Soc. Géol. France. 178:73-90 (2007)

4. F. Collin, P. Kotronis, B. Pardoen. Numerical Modeling of Multiphysics Couplings and Strain Localization. Chapter 7 in Instabilities Modeling in Geomechanics. (SCIENCES, ISTE, 2020)

5. B. Pardoen, F. Collin. Modelling the influence of strain localisation and viscosity on the behaviour of underground drifts drilled in claystone. Comput. Geotech. 85:351-367 (2017)

6. B. Pardoen, J. Talandier, F. Collin. Permeability evolution and water transfer in the excavation damaged zone of a ventilated gallery. Int. J. Rock Mech. Min. 85:192-208 (2016) 
7. B. Pardoen, D.M. Seyedi, F. Collin. Shear banding modelling in cross-anisotropic rocks. Int. J. Solids Struct. 72:63-87 (2015)

8. B. Pardoen, S. Levasseur, F. Collin. Using Local Second Gradient Model and Shear Strain Localisation to Model the Excavation Damaged Zone in Unsaturated Claystone. Rock Mech. Rock Eng. 48:691-714 (2015)

9. R. Charlier, F. Collin, B. Pardoen, J. Talandier, J.P. Radu, P. Gerard. An unsaturated hydro-mechanical modelling of two in-situ experiments in Callovo-Oxfordian argillite. Eng. Geol. 165:46-63 (2013)

10. B. Pardoen. Hydro-mechanical analysis of the fracturing induced by the excavation of nuclear waste repository galleries using shear banding. (PhD thesis, ULg, 2015)

11. B. Pardoen, P. Bésuelle, S. Dal Pont, P. Cosenza, J. Desrues. Accounting for Small-Scale Heterogeneity and Variability of Clay Rock in Homogenised Numerical Micromechanical Response and Microcracking. Rock Mech. Rock Eng. 53:2727-2746 (2020)

12. B. Pardoen, S. Dal Pont, J. Desrues, P. Bésuelle, D. Prêt, P. Cosenza. Heterogeneity and variability of clay rock microstructure in a hydro-mechanical double scale FEMxFEM analysis. micro to MACRO Mathematical Modelling in Soil Mechanics. (2018)

13. B. Pardoen, P. Bésuelle, S. Dal Pont, P. Cosenza, J. Desrues. Effect of claystone small-scale characteristics on the variability of micromechanical response and on microcracking modelling. 16th Int. Conf. of IACMAG. (Torino, 2020)

14. A.P. van den Eijnden, P. Bésuelle, R. Chambon, F. Collin. A FE2 modelling approach to hydromechanical coupling in cracking induced localization problems. Int. J. Solids Struct. 97-98:475-488 (2016)

15. A.P. van den Eijnden, P. Bésuelle, F. Collin, R. Chambon, J. Desrues. Modeling the strain localization around an underground gallery with a hydro-mechanical double scale model; effect of anisotropy. Comput. Geotech. 85:384-400 (2017)

16. R. Chambon, D. Caillerie, T. Matsushima. Plastic continuum with microstructure, local second gradient theories for geomaterials: localization studies. Int. J. Solids Struct. 38:8503-8527 (2001)

17. F. Collin, R. Chambon, R. Charlier. A finite element method for poro mechanical modelling of geotechnical problems using local second gradient models. Int. J. Numer. Meth. Engng. 65:1749-1772 (2006)

18. G. Armand, A. Noiret, J. Zghondi, D.M. Seyedi. Short- and long-term behaviors of drifts in the Callovo-Oxfordian claystone at the Meuse/Haute-Marne Underground Research Laboratory. J. Rock Mech. Geotech. Eng. 5:221230 (2013)

19. P. Gerard, R. Charlier, R. Chambon, F. Collin. Influence of evaporation and seepage on the convergence of a ventilated cavity. Water Resour. Res. 44:1-16 (2008)

20. P. Cosenza, D. Prêt, A. Giraud, S. Hedan. Effect of the local clay distribution on the effective elastic properties of shales. Mech. Mater. 84:55-74 (2015)

21. J.C. Robinet, P. Sardini, D. Coelho, J.C. Parneix, D. Prêt, S. Sammartino, E. Boller, S. Altmann. Effects of mineral distribution at mesoscopic scale on solute diffusion in a clay-rich rock: Example of the Callovo-Oxfordian mudstone (Bure, France). Water Resour. Res. 48:W05554 (2012)

22. G. Desbois, N. Höhne, J.L. Urai, P. Bésuelle, G. Viggiani. Deformation in cemented mudrock (Callovo-Oxfordian Clay) by microcracking, granular flow and phyllosilicate plasticity: insights from triaxial deformation, broad ion beam polishing and scanning electron microscopy. Solid Earth. 8:291-305 (2017)

23. J. Frey, R. Chambon, C. Dascalu. A two-scale poromechanical model for cohesive rocks. Acta Geotech. 8:107-124 (2013)
24. F. Marinelli, A van den Eijnden, Y. Sieffert, R. Chambon, F. Collin. Modeling of granular solids with computational homogenization: Comparison with Biot's theory. Finite Elem. Anal. Des. 119:45-62 (2016)

25. G. Armand, N. Conil, J. Talandier, D.M. Seyedi. Fundamental aspects of the hydromechanical behaviour of Callovo-oxfordian claystone: From experimental studies to model calibration and validation. Comput. Geotech. 85:277-286 (2017)

26. A. Di Donna, P. Charrier, S. Salager, P. Bésuelle. Selfsealing capacity of argillite samples. 7th International Symposium on Deformation Characteristics of Geomaterials. E3S Web Conf., 92, 03005 (2019) 